\title{
Dysregulated PDGFR alpha expression and novel somatic mutations in colorectal cancer: association to RAS wild type status and tumor size
}

Nadia Ben Jemii ${ }^{1,3^{*}} \mathbb{0}$, Haifa Tounsi-Kettiti ${ }^{2,3}$, Hamza Yaiche ${ }^{1,3}$, Najla Mezghanni ${ }^{1,3}$, Amira Jaballah Gabteni ${ }^{1,3}$, Emna Fehri ${ }^{1}$, Chayma Ben Fayala', Sonia Abdelhak ${ }^{3}$ and Samir Boubaker ${ }^{2,3}$

\begin{abstract}
Background: Platelet derived growth factor receptor alpha (PDGFRa) has been considered as a relevant factor in tumor proliferation, angiogenesis and metastatic dissemination. It was a target of tyrosine kinase (TK) inhibitors emerged in the therapy of diverse cancers. In colorectal cancer, the commonly used therapy is anti-epithelial growth factor receptor (EGFR). However, both RAS mutated and a subgroup of RAS wild type patients resist to such therapy. The aim of this study is to investigate PDGFRa protein expression and mutational status in colorectal adenocarcinoma and their association with clinicopathological features and molecular RAS status to provide useful information for the identification of an effective biomarker that might be implicated in prognosis and treatment prediction.

Methods: Our study enrolled 103 formalin fixed paraffin-embedded (FFPE) colorectal adenocarcinoma. PDGFRa expression was investigated by immunohistochemistry (IHC). Hotspot exon 18 of PDGFRA was studied by PCR followed by Sanger sequencing and RAS status was determined by real time quantitative PCR. Thirteen normal colon tissues were used as negative controls.

Results: PDGFRa staining was detected in the cytoplasm of all tissues. Low expression was observed in all normal colon mucosa. In adenocarcinoma, 45\% (45/100) of cases showed PDGFRa overexpression. This overexpression was significantly associated with mutations in exon $18(P=0.024)$, RAS wild type status $\left(P<10^{-3}\right)$, tumor diameter $(P=0.048)$, whereas there was no association with tumor side $(P=0.13)$ and other clinicopathological features.

Conclusion: Overexpression of PDGFRa in adenocarcinoma suggests its potential role in tumor cells growth and invasion. The association between PDGFRa overexpression in both tumor and stromal adenocarcinoma cells with RAS wild type status suggests its potential role in anti-EGFR therapy resistance and the relevance of using it as specific or adjuvant therapeutic target.
\end{abstract}

Keywords: Platelet derived growth factor receptor alpha, Colorectal cancer, RAS status, Mutations exon 18, Immunohistochemistry

*Correspondence: nadiabenjemii@gmail.com;

nadia.benjemii@pasteur.utm.tn

${ }^{1}$ Laboratory of Human and Experimental Pathology, Faculty of Science of Tunis, Institut Pasteur de Tunis, University Tunis El Manar, Tunis, Tunisia

Full list of author information is available at the end of the article

\section{Background}

Prognosis and treatment of the heterogeneous disease, colorectal cancer (CRC), is challenging. CRC is the third leading cause of death in the world as well as in Tunisia with an age-standardized incidence and mortality rates of respectively 19.7 and 8.9 in the world and of 11.9 and 6.6

c) The Author(s) 2020. This article is licensed under a Creative Commons Attribution 4.0 International License, which permits use, sharing, adaptation, distribution and reproduction in any medium or format, as long as you give appropriate credit to the original author(s) and the source, provide a link to the Creative Commons licence, and indicate if changes were made. The images or other third party material in this article are included in the article's Creative Commons licence, unless indicated otherwise in a credit line to the material. If material is not included in the article's Creative Commons licence and your intended use is not permitted by statutory regulation or exceeds the permitted use, you will need to obtain permission directly from the copyright holder. To view a copy of this licence, visit http://creativeco mmons.org/licenses/by/4.0/. The Creative Commons Public Domain Dedication waiver (http://creativecommons.org/publicdomain/ zero/1.0/) applies to the data made available in this article, unless otherwise stated in a credit line to the data. 
in Tunisia per 100,000 people (https://gco.iarc.fr/today/ home). The evaluation of the prognosis and the response to therapy in CRC is based on several factors including TNM stage, some histopathological criteria and molecular testing for Rat sarcoma (RAS) mutation to select patients for anti-EGFR targeted therapy. Currently there is an increasing concern that these factors are limited in their ability to reflect the diversity of clinical behavior of colorectal cancer and the response to targeted therapy. Hence, they are not sufficient to discriminate patients with different molecular pathological profiles.

Consensus molecular subtypes (CMS) classification and other new molecular biomarkers are studied to assess the diagnosis and the prognosis of CRC and other malignancies as methaderin and octamer-binding transcription factor 4 (Oct4), but still not recommended for patients management $[1,2]$.

Platelet derived growth factor (PDGF) signaling pathway promotes processes of cancer aggressiveness as epithelial mesenchymal transition (EMT), tumor proliferation, growth and progression, angiogenesis, inhibition of apoptosis, recurrence and metastatic dissemination via the activation of various signaling pathway as PI3K/AKT and RAS/MAPK signaling pathways [35]. Platelet-derived growth factor receptors (PDGFR) and their ligands were reported as highly expressed in consensus molecular subtypes 4 (CMS4) colon tumors and identified as potential therapeutic targets for this subtype [6]. Dysregulation of PDGFR alpha (PDGFR $\alpha$ ), one of receptors tyrosine kinase (RTK), has been reported in a broad range of cancer including glioblastoma, breast cancer, hepatocellular carcinomas, pancreatic cancer, and ovarian cancer [4, 7-9], either by protein overexpression or by the effect of mutations and chromosomal rearrangements. Moreover, this receptor has been approved by the Food and Drug Administration as therapeutic target for the treatment of patients with gastrointestinal stromal tumors (GISTs) (https://www.brimr.org/PKI/ PKIs.htm). It was shown that Imatinib (PDGFR $\alpha$ inhibitor) can reduce the aggressive phenotype of CMS4 class colorectal tumors $[6,10]$.

Anti-epidermal growth factor receptor (EGFR) monoclonal antibody was the therapy commonly used for metastatic colorectal cancer patients with wild-type RAS (KRAS/NRAS) genes. Nevertheless, 25\% of patients with RAS wild type (WT) status didn't respond to this therapy [11]. Resistance could be explained by genetic alterations in other ancillary axes signaling pathways governing tumor growth, in addition to the tyrosine kinase receptor EGFR, representing a cross-RTK signaling switching that cannot be captured by targeting single RTK [12]. Recent data have demonstrated that EGF stimulates EGFR-PDGFR $\alpha$ transactivation and heterodimerization
[13]. PDGFR $\alpha$ showed a crucial role in therapy resistance given its impact in both stromal and tumor cells which intensify tumor proliferation. In this context, genetic variabilities were identified in PDGFRA gene as associated to resistance toward anti-EGFR targeted therapy but the results still controversial $[14,15]$. Moreover, the EGFR and PDGFR signaling pathways share large downstream signaling pathways as the activation of RAS genes. As a result, molecular RAS status could influence the expression level or interferes also with TK inhibition of other RTK than EGFR, including the PDGF $\alpha$ receptor.

This work aimed to explore the PDGFR $\alpha$ expression/ mutational hot spot exon 18 status and its association with clinicopathological features and RAS status in colorectal adenocarcinoma in order to assess its potential role in prognosis and treatment prediction.

\section{Materials and methods}

\section{Patients and tissue samples}

A total of 116 formalin fixed and paraffin embedded (FFPE) tissues including 103 colorectal adenocarcinoma, and 13 normal colon mucosa as negative controls were collected from the archived tissues in Department of Human and Experimental pathology at Institut Pasteur de Tunis. Histological reports including tumor location, histological gradation and TNM status were collected.

\section{Pretreatment of formalin fixed and paraffin-embedded samples}

For each sample, six sections of $4 \mu$ m-thick were obtained, 3 sections for DNA extraction, 2 sections for histopathological study (the first and the last sections to check the presence of tumor cells) and $1 \mathrm{sec}-$ tion for immunohistochemical study. After each specimen, blades were changed to minimize the risk of cross-contamination.

\section{Histopathological study}

Samples were stained with hematoxylin-eosin (HE) and examined by a Pathologist to confirm the histopathological diagnosis and to assess the proportion of tumor cells.

\section{Immunohistochemistry}

Sections were deparaffinized in toluene, rehydrated with ethanol, and immersed in citrate antigenic retrieval buffer during $20 \mathrm{~min}$ in $95^{\circ} \mathrm{C}$ water-bath and then cooled at room temperature for $20 \mathrm{~min}$. Endogenous peroxidase activity was subsequently blocked with $3 \%$ hydrogen peroxide in methanol followed by incubation with protein block for $30 \mathrm{~min}$. The sections were incubated with the primary antibody: anti-PDGFR $\alpha$ antibody (1:100; Santa Cruz Biotechnology, Inc.) for $1 \mathrm{~h}$ at room temperature. After phosphate-buffered saline (PBS) washing, tissue 
sections were incubated with biotinylated secondary antibody during $30 \mathrm{~min}$, followed by incubation with novolink polymer (Leica Microsystems, Newcastle Ltd.) for $30 \mathrm{~min}$. The antibody complex was visualized by the chromogens 3-amino-9-ethylcarbazole (AEC) and sections were counterstained with Mayer's hematoxylin. Prostate tissue from department of Human and Experimental pathology of Institut Pasteur de Tunis was used as a positive control for primary antibody. For negative controls, the anti-PDGFR $\alpha$ antibody was replaced by PBS.

\section{Evaluation of immunohistochemical data}

Tumoral and stromal cells were scored by a pathologist using the immuno-reactive-score (IRS) system. IRS system is the product of the staining intensity and the proportion of the positive stained tumor cells in comparison with negative tumor cells. Only cytoplasmic and or membranous staining were considered. Labeling intensity was scored from 0 to 3 as follow; 0: absence of staining, 1: weak staining, 2: moderate staining and 3: strong staining. The percentage of positive stained tumor cells was graded as follows: 0 for less than $10 \%$ of positive tumor cells, 0.5 for $10-50 \%$, and 1 for more than $50 \%$ of positive tumor cells. The final scores obtained were $0 ; 0.5 ; 1$; 1.5; 2 and 3. According to this score, PDGFR $\alpha$ expression was classified into two categories: low expression $(\mathrm{IRS}=0-0.5)$ and high expression $(\mathrm{IRS}=1-3)$.

\section{Molecular analysis}

- DNA extraction and quantification

DNA extraction from paraffin blocks was performed using the Qiagen (QIA) amp DNA Mini Kit (Qiagen, Courtaboeuf, France) according to the manufacturer's instructions. DNA concentrations and purities were determined using a NanoDrop 2000c spectrophotometer (Thermo Fisher Scientific, Wilmington, Delaware).

- RAS mutation analysis

The KRAS/NRAS mutational analysis was performed by the LightMix kit (TibMolBiol) according to the manufacturer's instructions. Briefly, 3 probes (CTRL No-Clamped Control, LOW Clamped Mutation Analysis and HIGH Clamped Mutation Analysis) were used to detect specific mutations in the codons $12-13$ of the second (first transcribed) exon of the KRAS gene. Whereas, 6 probes (N12-13, N5961, N117, N146, K117 and K146) were used to identify mutations in the codons 12-13 (exon 2), codons 59-61 (exon 3), codon 117 and 146 (exon 4) of NRAS gene as well as codons 117 and 146 (exon 4) of the KRAS gene. Reaction mix was then inserted into
Roche Diagnostics Light-Cycler instrument 480 to detect specific mutations.

- Exon 18 PDGFRA PCR amplification

According to the Catalogue of Somatic Mutations in Cancer (COSMIC) database, the exon 18 of the PDGFRA gene is a hotspot pathogenic mutation site. Polymerase chain reaction (PCR) was performed using specific primer pair (Forward: 5' GATCAGCCAGTC TTGCAG 3'; Reverse: 5' CTCTAGAAGCAACAC CTGAC $3^{\prime}$ ) covering 79 base pair (bp) of the intron $17-18$, the totality of the exon 18 (123 bp) and $77 \mathrm{bp}$ of the intron 18-19 of PDGFRA gene. The design of primers was carried out using the software "primer designing tools" by accessing the website "https:// www.ncbi.nlm.nih.gov/tools/primer-blast/".

Extracted DNA was subjected to a PCR with the following parameters: $15 \mathrm{~min}$ initial denaturation at $94{ }^{\circ} \mathrm{C}$, followed by 35 amplification cycles of $45 \mathrm{~s}$ at $94{ }^{\circ} \mathrm{C}, 45 \mathrm{~s}$ at $58{ }^{\circ} \mathrm{C}$ and $45 \mathrm{~s}$ at $72{ }^{\circ} \mathrm{C}$, and a final extension step of $10 \mathrm{~min}$ at $72{ }^{\circ} \mathrm{C}$, using a thermal cycler (BIORAD T100TM Thermal cycler, Life science research). The PCR products were then subjected to electrophoresis in a $1.5 \%$ agarose gel with syber safe.

- Exon 18 PDGFRA sanger sequencing

The PCR products were sequenced on an automated sequencer (ABI 3500; Applied Biosystems, Foster City, CA, USA), using a cycle sequencing reaction kit (Big Dye Terminator kit, Applied Biosystems). Data were analyzed using the BioEdit Sequence Alignment Editor Version 7.0.5.3.

- Prediction tools

PDGFRA mutations were predicted with different computational tools (Mutation taster: https://www. mutationtaster.org/, Human Splicing Finder (HSF): https://umd.be/Redirect.html, Sorting Intolerant From Tolerant (SIFT): https://sift.bii.a-star.edu. sg/, Protein Variation Effect Analyzer (PROVEAN): https://provean.jcvi.org/protein_batch_submi t.php?species=human, Catalogue of Somatic Mutations in Cancer (COSMIC): https://cancer.sanger.ac. uk/cosmic, Ensembl: https://www.ensembl.org/index .html, UMD predictor: https://umd-predictor.eu/ analysis.php and ClinVar: https://www.ncbi.nlm.nih. gov/clinvar/ in order to estimate splice site effects, protein damage or clinical signification. An online web-server HOPE was used to analyze the effects of point mutations on protein hydrophobicity, chemical and physical properties, spatial structure and function (https://www.cmbi.ru.nl/hope/) [16]. Moreover, effects of synonymous mutations on messenger ribonucleic acid (mRNA) folding were predicted using Mfold web server (https://www.bioinfo.rpi.edu/appli 
cations/mfold) [17]. The full mRNA sequence of PDGFRA (reference and mutated) and 123pb nucleotide sequence surrounding the synonymous variation were analyzed. To predict the amount of structural SNP, differences in single-strandedness count (sscounts) (number of times each nucleotide is single stranded in a group of predicted foldings) were analyzed for each synonymous variation relative to the reference sequence in both full and partial sequence [18]. The most stable structure (having the lowest Gibbs free energy $(\Delta G)$ was used for analysis.

\section{Statistical analysis}

IBM SPSS Statistics version 26.0 was used for all statistical analysis. Fisher's exact test or $X^{2}$ test was performed to analyze association between PDGFR $\alpha$ expression, clinicopathological parameters, RAS status and molecular PDGFRA status. $\mathrm{P}<0.05$ was considered as statistically significant and $\mathrm{P}<0.001$ highly significant in all statistical analyses.

\section{Results}

\section{Samples features}

One hundred and three adenocarcinomas and 13 normal colon tissues were analyzed. The age of patients ranged from 22 to 88 years, with an average age of 57.4 years (SD, 13.2). There was a slight male predominance (63 male and 40 female) with a sex ratio equal to 1.5 . Most of the adenocarcinomas were at stage pT3 (54/99 cases (54.5\%) and left side located (49/98 cases (50\%). Histological study showed that the moderately differentiated adenocarcinoma was the most frequent histological subtype (64.1\%). Table 1 summarizes clinicopathological data of the study series.

\section{Immunohistochemical PDGFRa expression}

The staining of PDGFR $\alpha$ was found in epithelial, endothelial and stromal (mononuclear elements of the stroma) cells. All normal colon mucosa showed low $(\mathrm{IRS}=0-0.5) \quad$ PDGFR $\alpha$ cytoplasmic staining strengthened by membranous immunolabelling (Fig. 1). In adenocarcinoma, 3 cases were eliminated because of nuclear staining. Among the remaining 100 samples, PDGFR $\alpha$ epithelial overexpression (IRS $=1-3$ ) was found in $45 \%$ (45/100) and low expression in 55\% (55/100) (Fig. 1). The expression pattern in ADK showed cytoplasmic staining in all cases, among them, 2 samples $(0.02 \%)$ showed membranous and cytoplasmic labelling. These labellings were observed in low expression cases. PDGFR $\alpha$ overexpression was significantly associated to adenocarcinoma compared to normal tissues $(\mathrm{P}=0.001)$. Focal to diffuse immunostaining of immune infiltrate and vessels was shown in the tumor microenvironment (Fig. 1).

\begin{tabular}{|c|c|}
\hline Tissue samples & $N(\%)$ \\
\hline Total number & 103 \\
\hline \multicolumn{2}{|l|}{ Gender } \\
\hline Female & $40(38.8 \%)$ \\
\hline Male & $63(61.2 \%)$ \\
\hline \multicolumn{2}{|l|}{ Location } \\
\hline \multicolumn{2}{|l|}{ Colon } \\
\hline Right-side & $29(29.6 \%)$ \\
\hline Left-side & $49(50 \%)$ \\
\hline Rectum & $20(20.4 \%)$ \\
\hline Total & 98 \\
\hline \multicolumn{2}{|l|}{ Diameter of tumor } \\
\hline$\leq 5 \mathrm{~cm}$ & $54(60.7 \%)$ \\
\hline$>5 \mathrm{~cm}$ & $35(39.3 \%)$ \\
\hline Total & 89 \\
\hline \multicolumn{2}{|l|}{ Invasion of tumor } \\
\hline T1 & $1(1 \%)$ \\
\hline $\mathrm{T} 2$ & $7(7.1 \%)$ \\
\hline T3 & $54(54.5 \%)$ \\
\hline T4 & $37(37.4 \%)$ \\
\hline Total & 99 \\
\hline \multicolumn{2}{|l|}{ Lymph node metastasis } \\
\hline No & $35(35.4 \%)$ \\
\hline N1 & $34(34.3 \%)$ \\
\hline N2 & $30(30.3 \%)$ \\
\hline Total & 99 \\
\hline \multicolumn{2}{|l|}{ Histological grade } \\
\hline Well differentiated & $25(24.3 \%)$ \\
\hline Moderately differentiated & $66(64.1 \%)$ \\
\hline Poorly differentiated & $12(11.7 \%)$ \\
\hline Total & 103 \\
\hline
\end{tabular}

In adenocarcinoma stromal cells, 45\% (45/100) of cases showed PDGFR $\alpha$ overexpression, 52\% (52/100 cases) showed a low expression and 3\% (3/100 cases) showed an absence of PDGFR $\alpha$ expression. Significant association was observed between PDGFR $\alpha$ overexpression in epithelial and stromal adenocarcinoma cells $\left(\mathrm{P}<10^{-3}\right)$.

With regards to clinicopathological features, PDGFR $\alpha$ overexpression observed in $45 \%$ of epithelial colorectal ADK was significantly associated with tumor diameter $\leq 5 \mathrm{~cm}(\mathrm{P}=0.048)$. No association was found between PDGFR $\alpha$ overexpression and other clinicopathological factors as shown in Table 2.

\section{Mutational RAS/PDGFRA analysis}

CRC patients were examined for molecular RAS (KRAS/NRAS) status resulting in $47.5 \%$ (49/103) with 

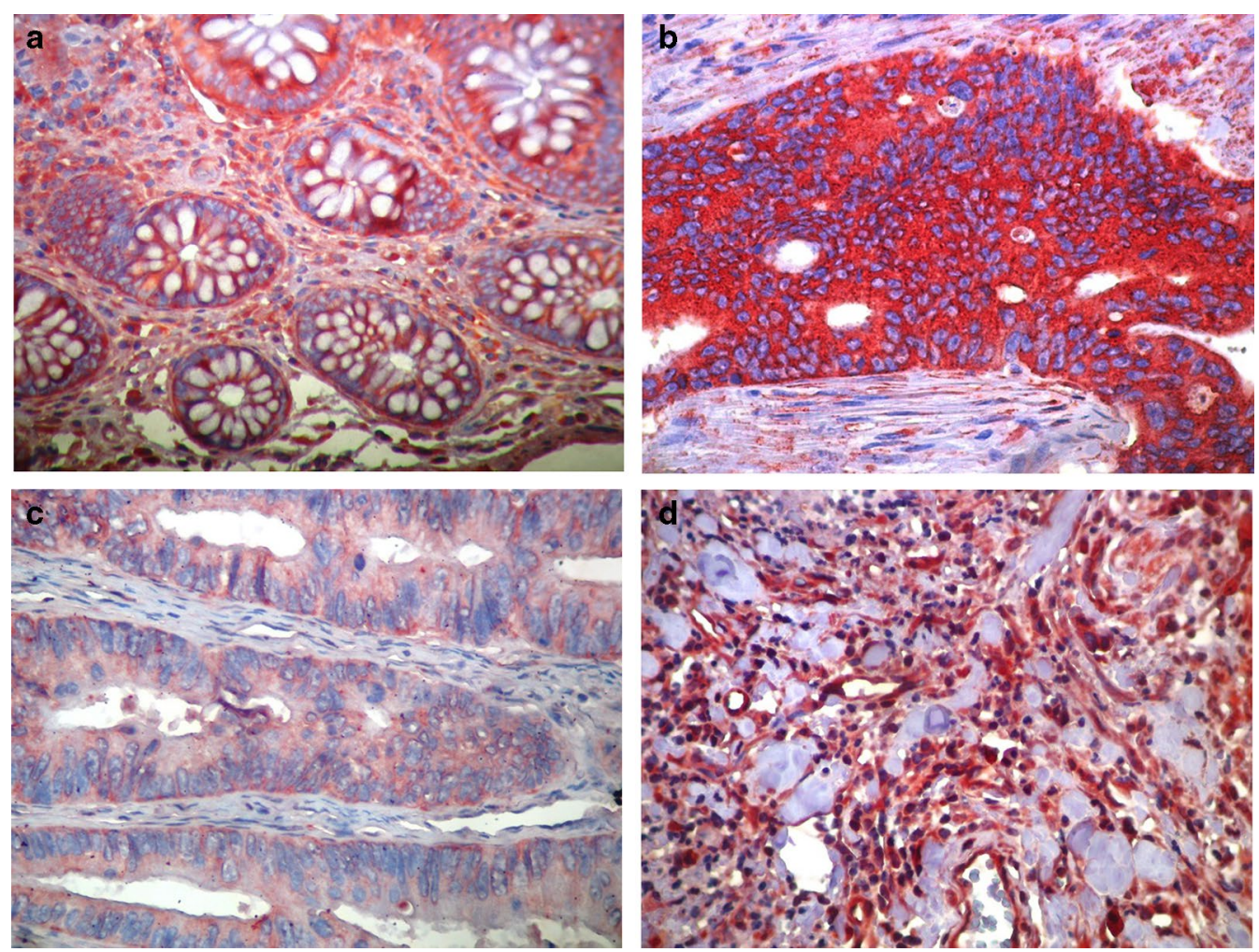

Fig. 1 PDGFRa immunohistochemical expression pattern. a Weak staining of PDGFRa in normal colon epithelium. b Strong staining of PDGFRa in wild type RAS adenocarcinoma. $\mathbf{c}$ Weak staining of PDGFRa in mutated RAS adenocarcinoma. $\mathbf{d}$ Diffuse immunostaining in stromal cells (a-c magnification $\times 200$; d magnification $\times$ 400)

RAS wild type (WT) status and 52.4\% (54/103) with mutated RAS status. The mutations were found in KRAS exon 2 gene in $44.6 \%(46 / 103)$ and in KRAS exon 3, 4; NRAS exons 2, 3, 4 gene in 7.7\% (8/103). RAS WT status was highly associated to PDGFR $\alpha$ overexpression $\left(\mathrm{P}<10^{-3}\right)$ (Table 2).

The mutational analysis of the exon 18 of PDGFRA gene was done in $55 \mathrm{ADK}$ and 3 normal samples. It revealed the presence of 18 variants, 5 in the intron $17-18,10$ in the exon 18 and 3 in the intron 18-19. Variant IVS17-50insA insertion ( $r$ s3830355) in intron 17-18 was found in all normal samples and in 53/55 ADK. All variations detected in the exon 18 and in the part of the intron 18-19 were absent in normal colon tissues. Among 10 mutations observed in the exon 18, 4 were non-synonymous and 6 were not reported previously. The Table 3 summarizes the characteristics of the different variations using different prediction tools.

Mutations in exon 18 were significantly associated only with PDGFR $\alpha$ overexpression $(\mathrm{P}=0.024)$ and mutations in the intron 18-19 were significantly associated with well differentiated adenocarcinoma $(P=0.035)$ (Table 4$)$. There was no association otherwise between different variations in PDGFRA gene and clinicopathological characteristics (Table 4).

\section{Effect of the mutations on the protein structure and function}

We found four non-synonymous mutations in the exon 18 (c.2464C > T, c. $2464 \mathrm{C}>\mathrm{A}$, c. $2459 \mathrm{C}>\mathrm{T}, \mathrm{c} .2507 \mathrm{~A}>\mathrm{T}$ ) which spatial effect on protein domain are shown in Fig. 2. In fact, the c. $2464 \mathrm{C}>\mathrm{T}$ and c. $2464 \mathrm{C}>\mathrm{A}$ mutations change the Arginine at position 822 into a cysteine and a serine respectively. These mutations share the same properties: the mutant residue is smaller, has a neutral charge and is more hydrophobic than the wild-type residue. Their localization within a protein kinase domain will cause loss of hydrogen bonds in the core of the protein and as a result disturbs correct folding. Moreover, these mutations are located in an important domain for the protein activity which is in contact with other domains involved in binding or in protein activity. The interaction between these domains could be disturbed by these mutations, which might affect protein function or signal transduction. The mutation c.2459C $>\mathrm{T}$ change the alanine into a Valine 
Table 2 Association between PDGFRa expression, clinicopathological parameters and RAS mutational status

\begin{tabular}{|c|c|c|c|}
\hline \multirow[t]{2}{*}{ Tissue samples } & \multicolumn{2}{|c|}{ PDGFRa expression } & \multirow[t]{2}{*}{$P$ value } \\
\hline & Low $(n=55)$ & High $(n=45)$ & \\
\hline Age (years) & & & 0.447 \\
\hline$<50$ & $13(59.1 \%)$ & $9(40.9 \%)$ & \\
\hline$\geq 50$ & $37(54.4 \%)$ & 31 (45.6\%) & \\
\hline Missing & 5 & 5 & \\
\hline Gender & & & 0.104 \\
\hline Male & $30(49.2 \%)$ & $31(50.8 \%)$ & \\
\hline Female & $25(64.1 \%)$ & $14(35.9 \%)$ & \\
\hline Missing & 0 & 0 & \\
\hline Location & & & 0.13 \\
\hline Colon & $43(57.3 \%)$ & $32(42.7 \%)$ & \\
\hline Rectum & $8(40 \%)$ & $12(60 \%)$ & \\
\hline Missing & 4 & 1 & \\
\hline Diameter of tumor (cm) & & & 0.048 \\
\hline$\leq 5$ & $23(45.1 \%)$ & $28(54.9 \%)$ & \\
\hline$>5$ & $23(65.7 \%)$ & $12(34.3 \%)$ & \\
\hline Missing & 9 & 5 & \\
\hline Invasion of tumor & & & 0.644 \\
\hline $\mathrm{T} 1$ & $1(100 \%)$ & $0(0 \%)$ & \\
\hline $\mathrm{T} 2$ & $3(50 \%)$ & $3(50 \%)$ & \\
\hline T3 & $30(56.6 \%)$ & $23(43.4 \%)$ & \\
\hline T4 & $17(47.2 \%)$ & $19(52.8 \%)$ & \\
\hline Missing & 4 & 0 & \\
\hline Lymph node metastasis & & & 0.54 \\
\hline NO & $20(60.6 \%)$ & $13(39.4 \%)$ & \\
\hline N1 & $18(54.5 \%)$ & 15 (45.5\%) & \\
\hline N2 & $14(46.7 \%)$ & $16(53.3 \%)$ & \\
\hline Missing & 3 & 1 & \\
\hline Histological gradation & & & 0.068 \\
\hline Well differentiated & $18(72 \%)$ & $7(28 \%)$ & \\
\hline Moderately differentiated & $33(52.4 \%)$ & $30(47.6 \%)$ & \\
\hline Poorly differentiated & $4(33.3 \%)$ & $8(66.7 \%)$ & \\
\hline Missing & 0 & 0 & \\
\hline RAS status & & & 0.000 \\
\hline Wild type & $17(35.4 \%)$ & $31(64.6 \%)$ & \\
\hline Mutated & $38(73.1 \%)$ & $14(26.9 \%)$ & \\
\hline Missing & 0 & 0 & \\
\hline
\end{tabular}

at position 820 . The mutant residue is bigger than the wild-type residue. This mutation, located within a domain tyrosine kinase, introduces an amino acid with different properties, which can disturb this domain and abolish its function. The c.2507A $>\mathrm{T}$ mutation changes an aspartic acid into a valine at position 836 . This mutant residue is smaller, has a neutral charge and is more hydrophobic than the wild-type residue. The difference in properties between wild-type and mutation can easily disturb ionic, domains and ligand interaction which might affect protein function and structure.

Our results showed also the presence of 6 synonymous variations (c.2472C $>$ T, c. $2481 \mathrm{~A}>\mathrm{T}$, c. $2496 \mathrm{G}>\mathrm{A}$, c. $2514 \mathrm{C}>\mathrm{T}$, c. $2517 \mathrm{G}>\mathrm{T}$ and c. $2520 \mathrm{C}>\mathrm{A})$. Except the c. $2481 \mathrm{~A}>\mathrm{T}$, these variations were predicted to induce splicing site alteration by HSF tool (Table 3). In order to test if they change mRNA secondary structure, we used Mfold web server. All synonymous variations changed ss-count as compared to the full length and the partial reference sequence which might change the mRNA secondary structure except for the c.2517G $>\mathrm{T}$ (data not mentioned). Partial mRNA folding structure of mutant compared to their wild type sequence were shown in Fig. 3. The mRNA folding carrying c. $2517 \mathrm{G}>\mathrm{T}$ was similar to that of WT. Other synonymous variations may lead to the change of mRNA secondary structure.

\section{Discussion}

To our knowledge, this is the first study investigating PDGFR $\alpha$ protein expression and molecular profiles in colorectal cancer and correlating these profiles with clinicopathological features and RAS status.

\section{PDGFRa staining pattern and mutational status in CRC}

In this work, immunohistochemistry results showed an immunostaining chiefly in the cytoplasm except for 2 ADK having membranous joined by cytoplasmic staining. These 2 cases have a low PDGFR $\alpha$ expression. Only cytoplasmic stain was found by Wehler and al using the same anti-PDGFR $\alpha$ antibody in all colorectal cancer samples studied [4]. They suggest that the cytoplasmic localization is the result of an impaired ubiquitination mechanism; possibly due to alterations undoing indirect link between PDGFR $\alpha$ and c-Cbl required and sufficient for endocytosis and lysosomal degradation $[4,19]$. PDGFR $\alpha$ cytoplasmic localisation might extend lifetime and/or execute specific functions as the activation of unconventional signaling pathways like STAT, c-Jun and PLCY pathways [20-24].

In the present study, we found that PDGFR $\alpha$ was weakly expressed in all control cases which is in accordance with other studies $[4,15,25-27]$.

In colorectal ADK, our results demonstrate the presence of PDFGR $\alpha$ in all cases which was in agreement with bibliographic data. In fact, Wehler et al. have found that PDGFR $\alpha$ was present in $82.8 \%$ (82/99 cases) of human colorectal cancer specimens [4]. In the same context, Schimanski et al. have found that PDGFR $\alpha$ was expressed in $84.9 \%$ (79/93 cases) of human colorectal cancers [15]. The analysis of our series demonstrated that $45 \%$ (45/100) of ADK cases showed PDGFR $\alpha$ overexpression which was significantly associated to ADK 


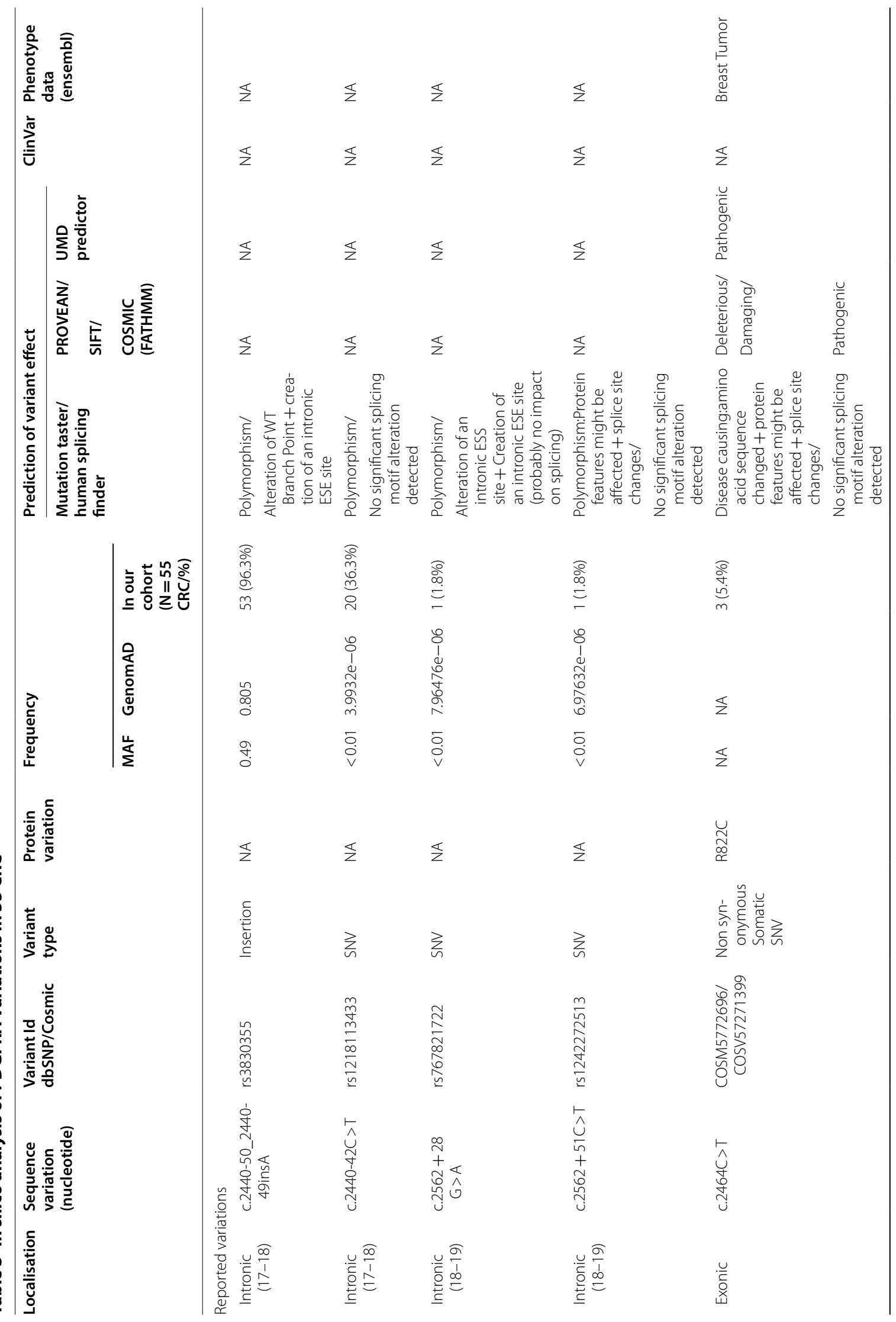




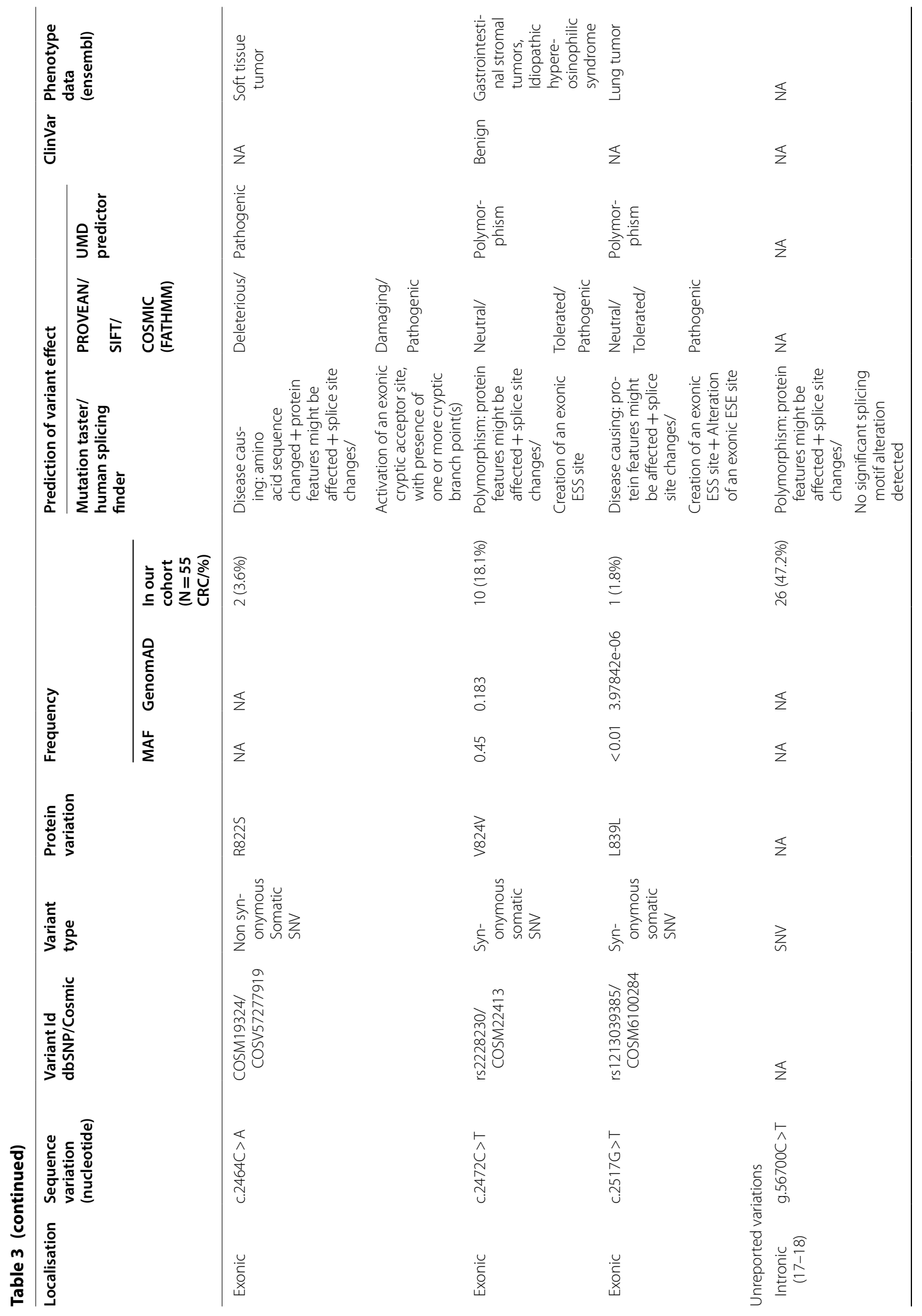




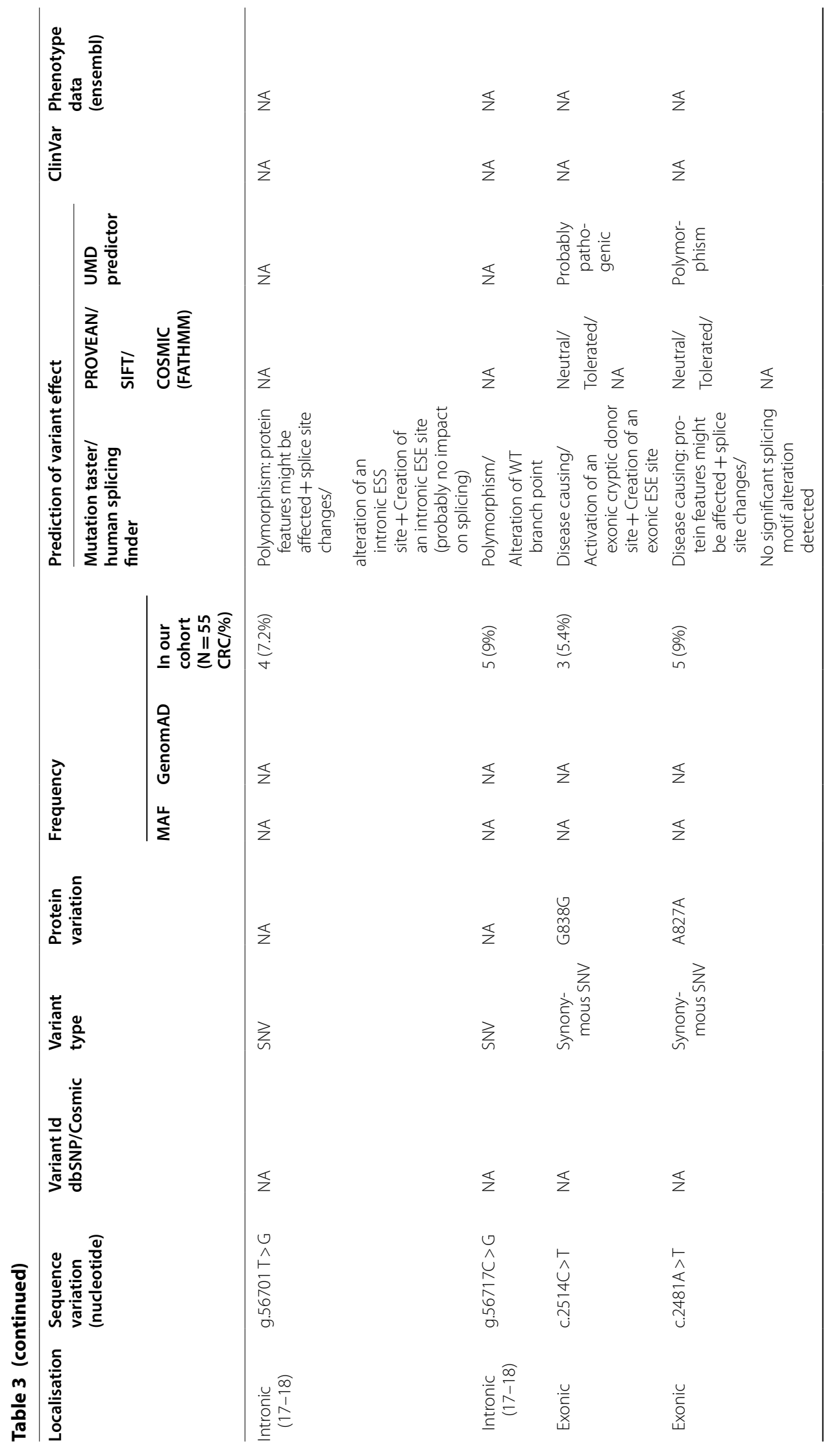




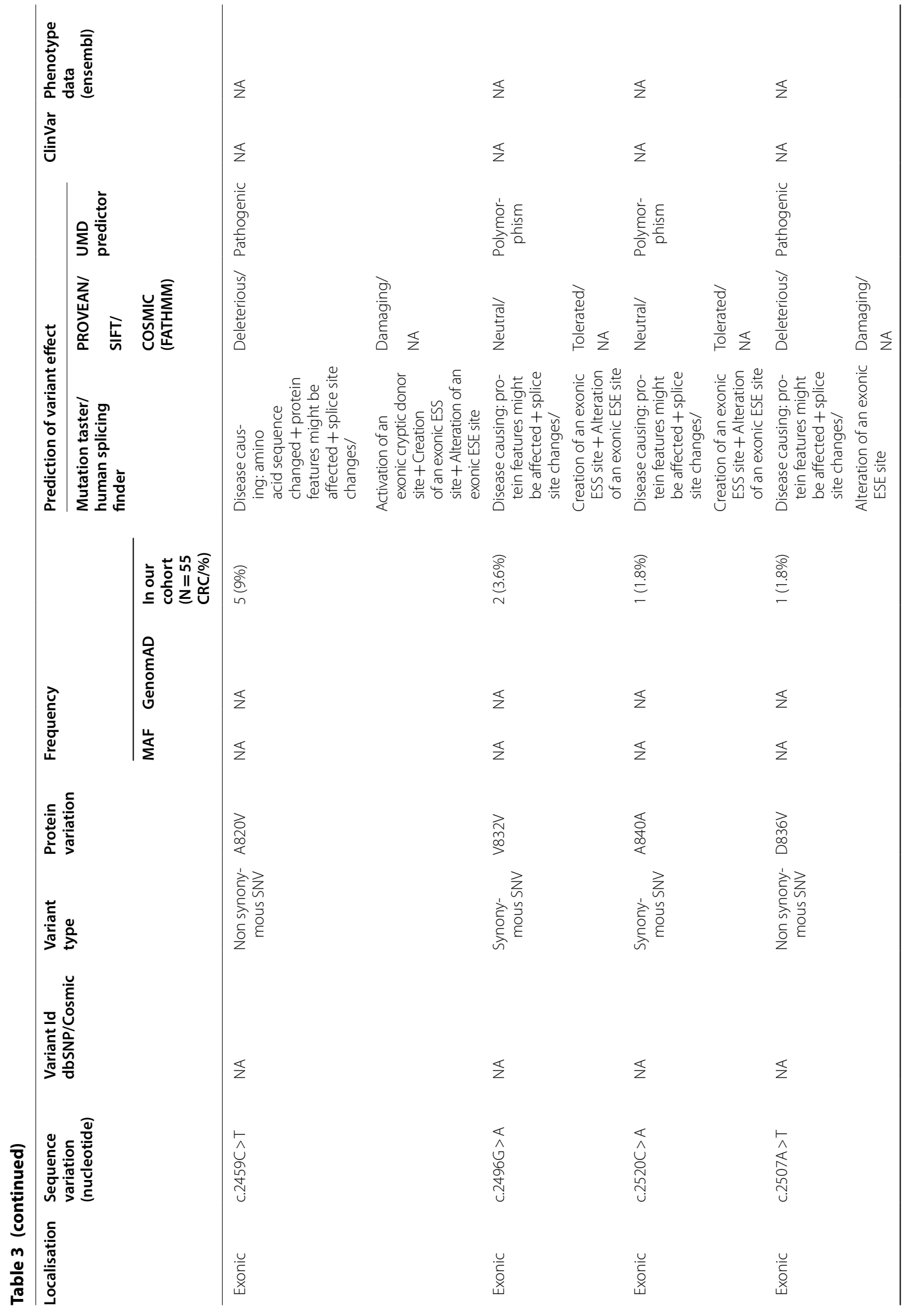




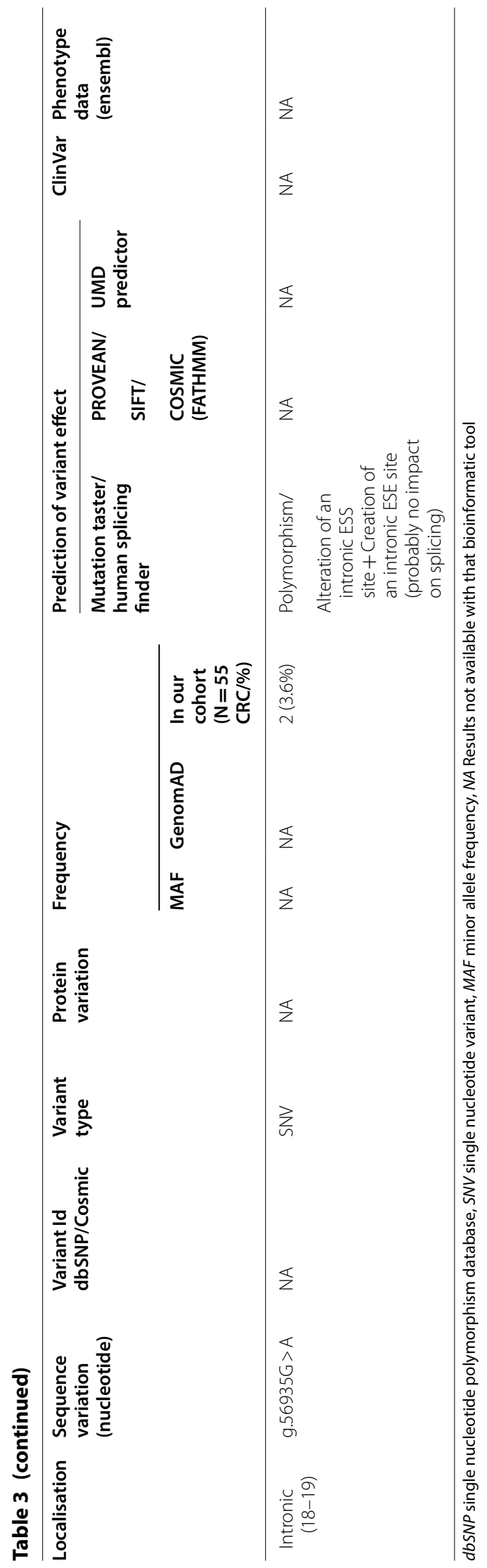


Table 4 Association between PDGFRA mutational status and clinicopathological parameters, PDGFRa expression and RAS mutational status

\begin{tabular}{|c|c|c|c|c|c|c|}
\hline \multirow[t]{2}{*}{ Tissue samples ( $\mathrm{N}=55 \mathrm{CRC}$ ) } & \multicolumn{2}{|c|}{ PDGFRA intron 17-18 } & \multicolumn{2}{|c|}{ PDGFRA exon 18} & \multicolumn{2}{|c|}{ PDGFRA intron 18-19 } \\
\hline & Present & P-value & Present & P-value & Present & P-value \\
\hline Age (years) & & 0.239 & & 0.5 & & 0.643 \\
\hline$<50$ years & $7(70 \%)$ & & $4(40 \%)$ & & $0(0 \%)$ & \\
\hline$\geq 50$ years & $21(51.2 \%)$ & & $19(46.3 \%)$ & & $2(4.9 \%)$ & \\
\hline Gender & & 0.43 & & 0.55 & & 0.599 \\
\hline Male & $17(48.6 \%)$ & & $15(42.9 \%)$ & & $1(2.9 \%)$ & \\
\hline Female & $11(55 \%)$ & & $9(45 \%)$ & & $1(5 \%)$ & \\
\hline Location & & 0.119 & & 0.083 & & 0.339 \\
\hline Colon & $25(56.8 \%)$ & & $22(50 \%)$ & & $1(2.3 \%)$ & \\
\hline Rectum & $3(30 \%)$ & & $2(20 \%)$ & & $1(10 \%)$ & \\
\hline Diameter of tumor & & 0.521 & & 0.258 & & 0.635 \\
\hline$\leq 5 \mathrm{~cm}$ & $16(51.6 \%)$ & & $15(48.4 \%)$ & & $1(3.2 \%)$ & \\
\hline$>5 \mathrm{~cm}$ & 11 (55\%) & & $7(35 \%)$ & & $1(5 \%)$ & \\
\hline Invasion of tumor & & 0.228 & & 0.957 & & 0.952 \\
\hline $\mathrm{T} 2$ & $2(100 \%)$ & & $1(50 \%)$ & & $0(0 \%)$ & \\
\hline T3 & $16(55.2 \%)$ & & $13(44.8 \%)$ & & $1(3.4 \%)$ & \\
\hline $\mathrm{T} 4$ & $10(41.7 \%)$ & & $10(41.7 \%)$ & & $1(4.2 \%)$ & \\
\hline Lymph node metastasis & & 0.077 & & 0.924 & & 0.125 \\
\hline NO & $14(70 \%)$ & & $9(45 \%)$ & & $0(0 \%)$ & \\
\hline N1 & $6(33.3 \%)$ & & $7(38.9 \%)$ & & $2(11.1 \%)$ & \\
\hline $\mathrm{N} 2$ & $8(50 \%)$ & & $7(43.8 \%)$ & & $0(0 \%)$ & \\
\hline Histological gradation & & 0.283 & & 0.871 & & 0.035 \\
\hline Well differentiated & $9(69.2 \%)$ & & $5(38.5 \%)$ & & $2(15.4 \%)$ & \\
\hline Moderately differentiated & $16(47.1 \%)$ & & $15(44.1 \%)$ & & $0(0 \%)$ & \\
\hline Poorly differentiated & $3(37.5 \%)$ & & $4(50 \%)$ & & $0(0 \%$ & \\
\hline PDGFRa expression & & 0.089 & & 0.024 & & 0.103 \\
\hline Low & $16(43.2 \%)$ & & $4(22.2 \%)$ & & $2(11.1 \%)$ & \\
\hline High & $12(66.7 \%)$ & & $20(54.1 \%)$ & & $0(0 \%)$ & \\
\hline RAS status & & 0.333 & & 0.08 & & 0.666 \\
\hline Wild type & 15 (46.9\%) & & $17(53.1 \%)$ & & $1(3.1 \%)$ & \\
\hline Mutated & $13(56.5 \%)$ & & $7(30.4 \%)$ & & $1(4.3 \%)$ & \\
\hline
\end{tabular}

as compared to normal mucosa $(\mathrm{P}=0.001)$. Dai et al. revealed by cDNA microarray analysis of 16 cases of CRC and proximal non-cancerous colorectal mucosa, the overexpression of PDGFR $\alpha$ in colorectal cancers as compared to that in normal tissues (ratio $=4.81 \pm 0.14$ ) [26]. The same result was showed by Li et al. using the western blot analysis of 176 colon cancer specimens and normal biopsies [27]. Overexpression proportion variations could be the consequence of the use of different methodology, IHC scoring, and different number of cases. In this study, we used 103 cases of CRC and 13 cases as normal controls. This could explain the proportion difference of high expression regarding to normal controls.

Besides expression of PDGFR $\alpha$ in tumor colorectal cells, we noted the presence of focal to diffuse PDGFR $\alpha$ immunostaining in various mesenchymal stromal cells including inflammatory cells and vessels. In ADK stromal cells, our results showed that PDGFR $\alpha$ was expressed in 97\% (97/100 cases) of specimens. These were corroborated by previous results of Wehler et al. that showed PDGFR $\alpha$ expression in $70 \%$ of stromal colorectal carcinoma cells [4]. However, Bian et al. reported a moderately PDGFR $\alpha$ expression [25]. Our results showed an association between PDGFR $\alpha$ expression in tumor and stromal cells $\left(\mathrm{P}<10^{-3}\right.$, respectively). These results suggest that in ADK, stromal cells could intensify tumor growth. In fact, tumor-associated stroma formed by ostensibly normal cells was considered as active participants in tumorigenesis which leads to cancer progression and metastatic dissemination by interacting with cancer cells $[28,29]$. 


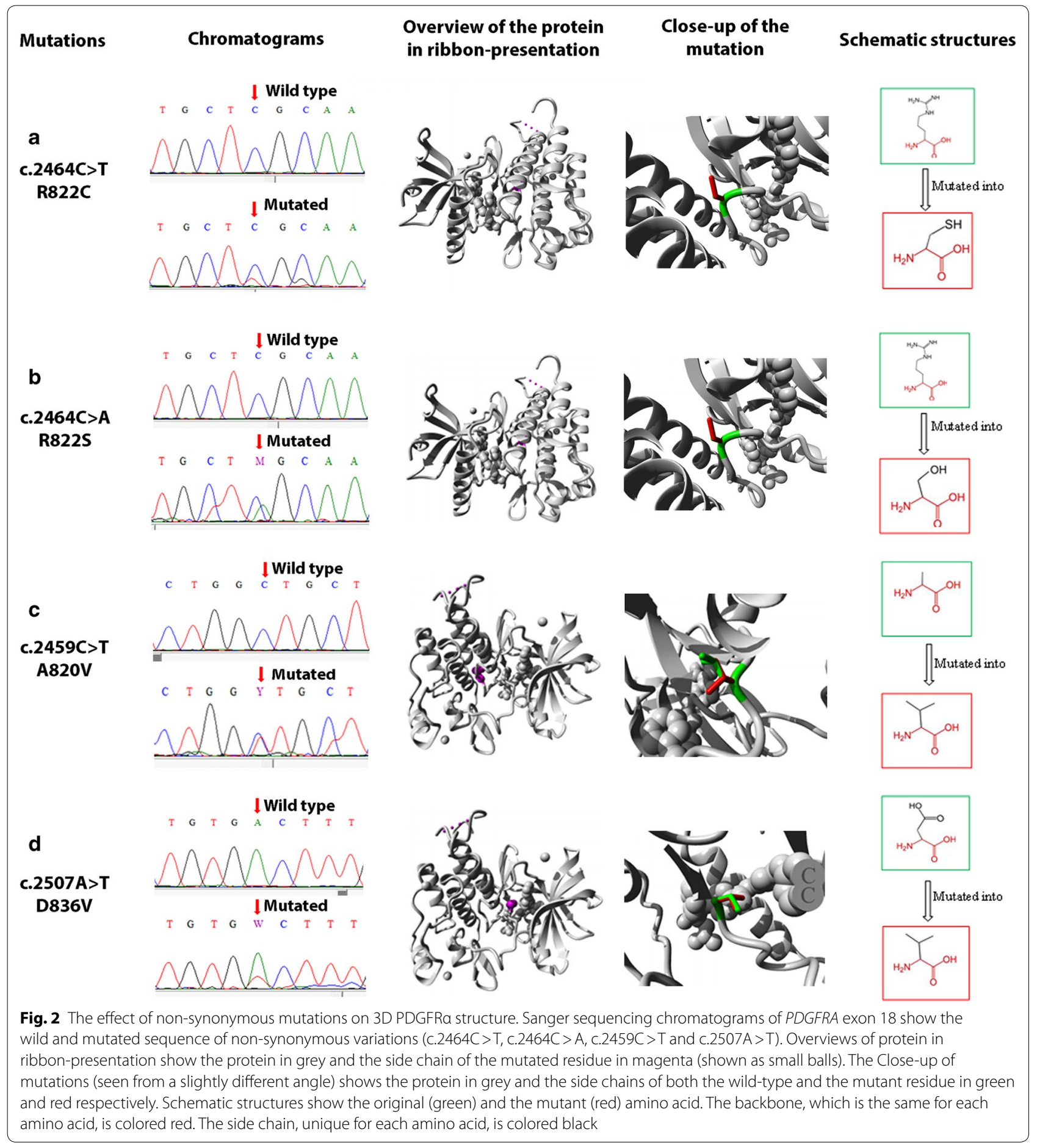

In our study, $54.1 \%$ of samples with PDGFR $\alpha$ present mutation in exon hotspot18 which encodes the tyrosine kinase domain II, a highly conserved region in PDGFRA gene. We noticed that mutations in the flanking intron parts have no impact on PDGFR $\alpha$ expression given the absence of association between these mutations and the overexpression of PDGFR $\alpha$. However, in the coding region, we have found 4 non synonymous mutations which changed 3D PDGFR $\alpha$ structure according to the HOPE web server (https ://www.cmbi.ru.nl/hope/). Two non-synonymous mutations were previously reported: the c. $2464 \mathrm{C}>\mathrm{T}$ 


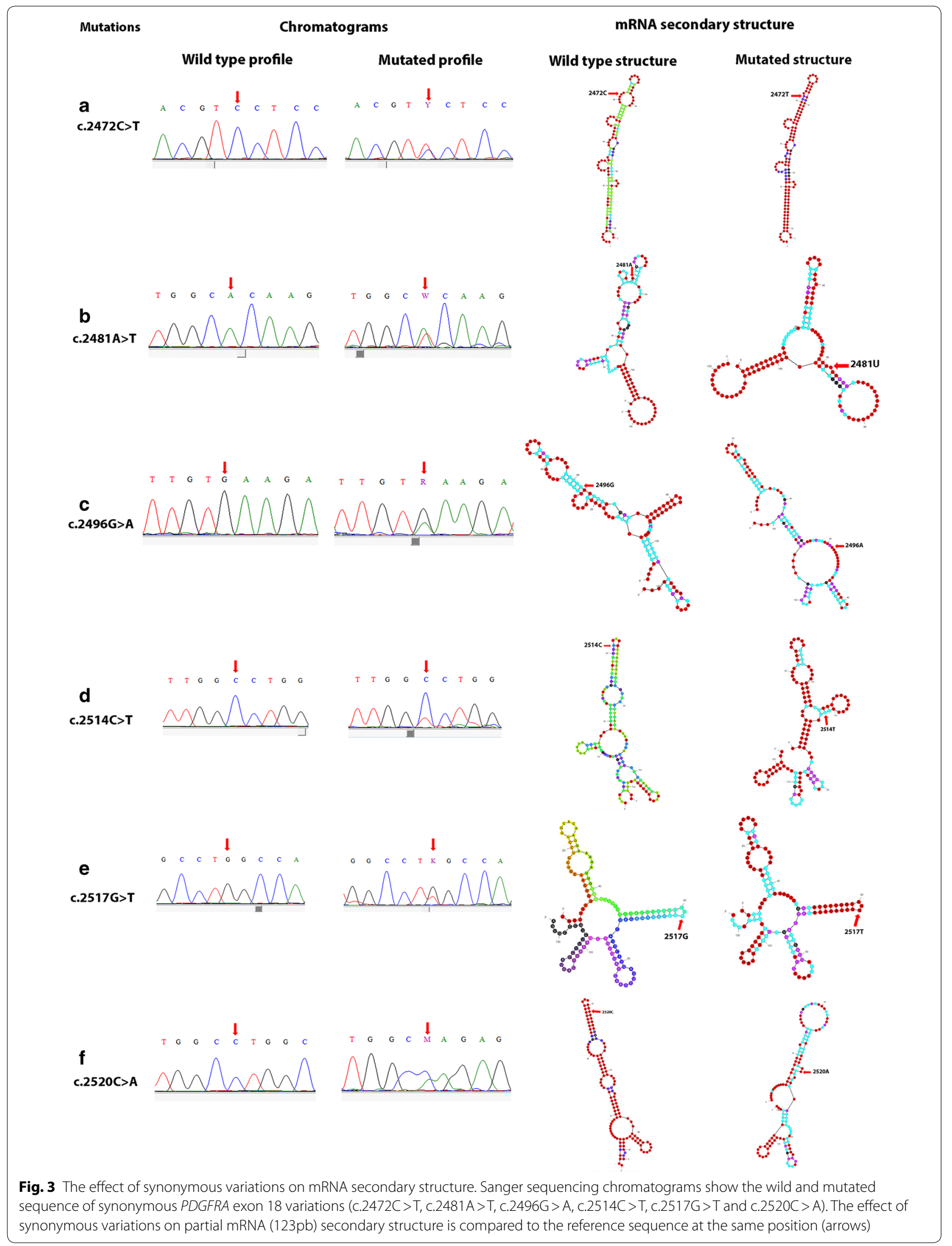


(COSM5772696) was described in colorectal cancer [14], as well as in other cancers [30] (COSMIC database: https://cancer.sanger.ac.uk/cosmic/gene/analy sis? $\ln =$ PDGFRA), and, the c.2464C $>$ A (COSM19324) identified only in gastrointestinal stromal tumor [31]. Our study also revealed the presence of 6 synonymous variations which might affect protein features, splicing sites or mRNA folding or stability according to mutation taster, HSF and mfold RNA prediction tools. Similar results were reported for other synonymous variation in CRC and other malignancy via the same mechanisms mentioned above [32-34]. This would have phenotypic effect on protein expression $[35,36]$. Our analysis showed a non-significant but a tendency toward association between the presence of synonymous variations and the PDGFR $\alpha$ overexpression $(\mathrm{P}=0.069$; data not shown $)$. However, it was shown by in vitro analysis that the synonymous polymorphism (c.2472C $>\mathrm{T}$ ), found in our study, reduces PDGFR $\alpha$ expression in acral melanoma via decreasing its mRNA and protein stability and its downstream signaling activity (MAPK and PI3K/AKT) [37]. In the same study, this polymorphism was associated to better survival [37]. However, it was reported as significantly associated with worse prognosis in renal cell carcinoma [38]. Effect of synonymous variation on protein expression could be the result of organ specificity. In our study, synonymous and non-synonymous mutations observed in the coding region of the PDGFRA gene were not observed in normal colon tissues. Therefore, the presence of these mutations in the coding conserved region could explain that high PDGFR $\alpha$ expression $(\mathrm{P}=0.024)$ might lead to colorectal carcinogenesis. In the same context, work on colorectal cancer has demonstrated the presence of other activating mutation as the $\mathrm{D} 842 \mathrm{~V}$ in the exon 18 in 2 of 322 ADK cases [39]. This mutation investigated for the determination of the response to Imatinib GIST therapy wasn't detected in our study. In contrast to our results, Shao et al. showed the absence of PDGFRA mutations in 46 human colorectal cancer samples [40].

Moreover, our results showed that $45.9 \%$ (17/37) of cases with PDGFR $\alpha$ overexpression have no mutation in the exon 18. Overexpression of PDGFR $\alpha$ in these cases could be explained by the presence of mutations in other exons of the gene $[14,39]$ or other activating mechanisms including gene amplification, autocrine loop activation, chromosomal alterations producing PDGFR $\alpha$ fusion with other gene and the deregulation of miRNA as miR-34a [4, 24, 27]. Increased PDGFR $\alpha$ expression could be caused also by the activating effect of signaling pathway as the Sonic Hedgehog pathway [41].

\section{PDGFRa expression and clinicopathological parameters}

In an attempt to explore the role of PDGFR $\alpha$ in neoplastic progression, we correlated its expression with clinicopathological parameters. Our study showed an association between high PDGFR $\alpha$ expression in ADK cells and tumor size $\leq 5 \mathrm{~cm}(P=0.048)$. Such association was not previously reported in colorectal cancer. The role of tumor diameter in CRC prognosis and recurrence remains controversial. In fact, several studies identified large tumor diameter as risk factor for recurrence, postoperative complications after laparoscopic surgery of advanced rectal cancer, metastasis and poor prognosis [42-45]. However, other studies revealed that small tumor size was associated to higher recurrence, poor survival and prognostic features [46-48]. According to the previous reports, correlation between PDGFR $\alpha$ overexpression and progressed International Union against Cancer (UICC) stages III/IV and lymph node metastasis was reported in older patients with colorectal sporadic cancer suggesting its important role in colorectal cancer dissemination [4]. However, our data showed no significant association between PDGFR $\alpha$ overexpression and $\mathrm{T}$ status $(\mathrm{P}=0.644), \mathrm{N}$ status $(\mathrm{P}=0.54)$, age class $(\mathrm{P}=0.447)$ or histological gradation $(\mathrm{P}=0.068)$. Furthermore, our results showed the absence of significant association $(\mathrm{P}=0.083)$ between the presence of mutations in exon 18 of ADK cases and the colon location. Several features identify colon and rectal cancer like complications, treatment, short-term mortality, long-term survival and recurrences [49]. Gene expression profiles and activating signaling pathways also vary according to tumor location as MAPK signaling pathway which was downregulated in rectal cancer [50]. PDGFR $\alpha$ was reported as highly expressed in CMS4 colon tumors [6]. This molecular subtype is composed mainly of left-sided primary tumors and tended to be diagnosed at stage III and IV [51, 52]. As a result, our findings suggest that PDGFR $\alpha$ may have an effect on colorectal cancer prognosis. Larger samples could improve the significance of the associations.

\section{Association between PDGFRa protein expression and mutational RAS status}

Our study showed that $64.5 \%$ (31/48 cases) of RAS WT ADK cases overexpressed PDGFR $\alpha\left(\mathrm{P}<10^{-3}\right)$ possibly due to the presence of mutations in PDGFRA exon $18(\mathrm{P}=0.08)$. These findings suggest that PDGFR $\alpha$ may represent a driver of tumor progression in RAS WT subgroup. In contrast to our results, Schimanski et al. have identified an association between PDGFR $\alpha$ expression and KRAS codon 12 or 13 mutation [15]. Currently, the use of EGFR targeted therapies in CRC is limited to patients with wild-type RAS genes. However, even with RAS WT status, resistance to this therapy occurs in $25 \%$ 
of patients [11]. Resistance could be explained by genetic alterations in other ancillary axes signaling other than EGFR pathway that cannot be captured by targeting single RTK [12]. Recent data have demonstrated that EGF stimulates EGFR-PDGFRA transactivation and heterodimerization [13]. The Fig. 4 generated by GeneMANIA bioinformatic analysis supported our hypothesis (https ://genemania.org/). This figure showed EGFR-PDGFRA physical interaction collected from primary studies found in protein interaction databases, including BioGRID and Pathway Commons [53].

Moreover, the EGFR and PDGFR $\alpha$ share large downstream signaling pathways as the activation of RAS/ MAPK pathway via various proteins (Fig. 5).

These evidences suggest that protein overexpression or genetic variabilities identified in PDGFRA exon 18 could explain this resistance. By analyzing the PDGFRA exon 18 mutations, we have detected the c.2464C $>\mathrm{T}$ mutation in 3 colorectal ADK cases all of which have WT RAS status. The c. $2464 \mathrm{C}>\mathrm{T}$ and other mutations among exons (16, 22, 19, 4, 7, 15, 8 and 10) were reported in CRC patients with KRAS WT status resistant to antiEGFR targeted therapy [14]. Li et al. reported that the absence of mutations in exon 18 and 15 of the PDGFRA gene and in other prognostic genes (KRAS, NRAS, BRAF and PIK3CA), showed a better response rate with antiEGFR therapy (cetuximab) [39]. As a result, given the existence of different activating mutations in the PDG$F R A$ gene and their high association with overexpression, immunohistochemistry could be used as a test to identify patients resistant toward anti-EGFR targeted therapy and prognostic prediction. It was demonstrated that the combination of PDGFR and EGFR inhibitors (imatinib versus cetuximab) in colorectal tumor graft with mutant PDGFRA R981H (exon 22), identified as a mechanism of primary resistance to EGFR blockade, has a strong antitumor activity but with a short-lived effect [14]. This non-significant combination could be the result of the existence of other mutations in the PDGFRA gene that cause resistance to imatinib therapy. Moreover, imatinib is a multi-receptors tyrosine kinase inhibitor so that it is not known to what degree their therapeutic effects are related to PDGFR $\alpha$ inhibition. As a result, it will be better to use specific neutralizing PDGFR $\alpha$ antibodies in combination with anti-EGFR therapy for patients with RAS WT status. Furthermore, our results showed

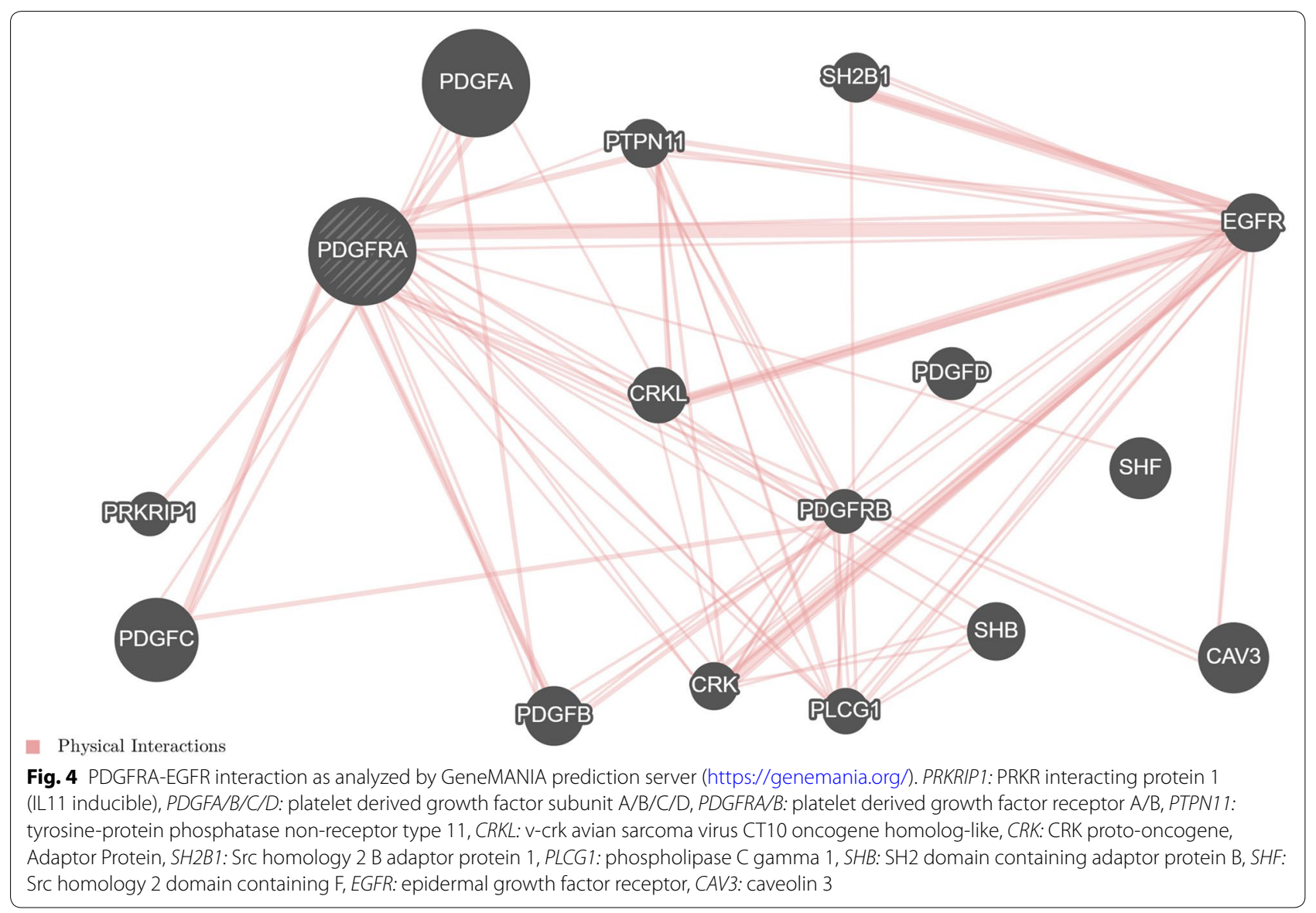




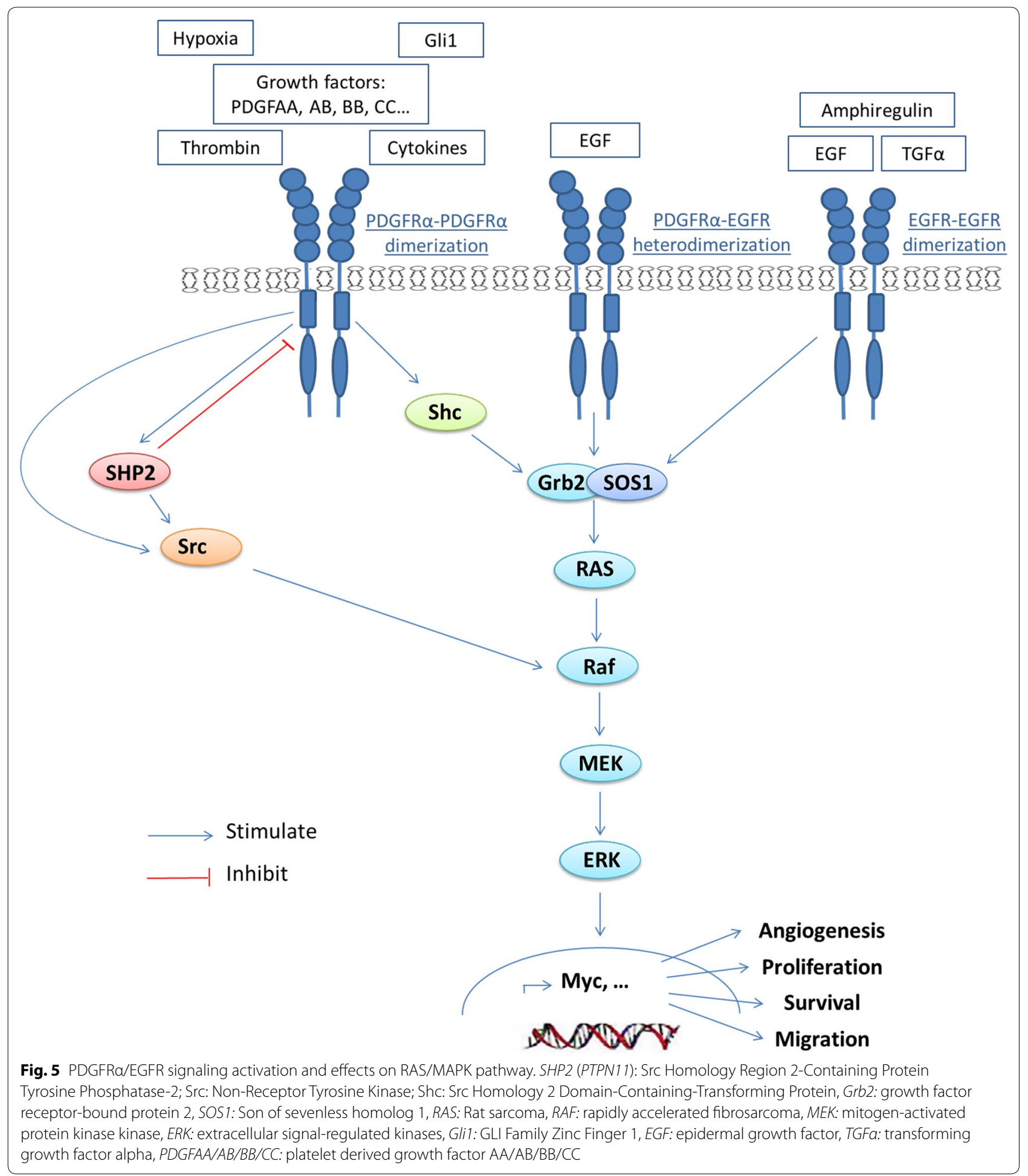

that 26.9\% (14/52 cases) of mutated RAS ADK cases overexpressed PDGFR $\alpha$. Bevacizumab (anti vascular endothelial growth factor (VEGF) therapy) is prescribed for colorectal cancer with RAS mutated status. Despite improving progression-free survival, the survival benefit of Bevacizumab remains limited due to the acquired resistance [54]. It was found that VEGF-A directly binds to PDGFR $\alpha$ and induce their activations [55]. PDGFR $\alpha$ 
overexpression might be one of resistance mechanisms. These findings suggest that specific neutralizing PDGFR $\alpha$ antibodies in combination with anti-VEGF therapy could be used for patients with mutated RAS status.

In order to validate these results, larger samples (controls and CRC tissues) and follow of response to targeted therapy are needed.

\section{Conclusion}

PDGFR $\alpha$ was significantly overexpressed in ADK compared to normal mucosa which may suggest its potential role in the development or the sustain of tumor cells. Furthermore, high PDGFR $\alpha$ expression was significantly associated to RAS WT status $\left(\mathrm{P}<10^{-3}\right)$ suggesting its role in the resistance to anti-EGFR and thus the possible inclusion of this protein in the panel of predictive biomarkers of response to anti-EGFR therapies. In another way, the fact that PDGFR $\alpha$ was expressed by tumor, surrounding stromal and endothelial cells, makes this receptor a good target by specific neutralizing antibodies. The cytoplasmic mislocalization of this receptor could confer to therapy a high degree of specificity. The IHC expression of PDGFR $\alpha$ could be a good option to select patients for associated anti PDGFR therapy. We should therefore study in more detail the genetic alteration of the whole PDGFRA gene which could be behind the alteration of its expression and its localization as well as determining the follow-up of patients with an overexpression of the PDGFR $\alpha$ protein and WT RAS status.

\begin{abstract}
Abbreviations
CRC: Colorectal cancer; ADK: Adenocarcinoma; CMS: Consensus molecular subtypes; PDGF: Platelet derived growth factor; PDGFR: Platelet derived growth factor receptor; EMT: Epithelial mesenchymal transition; RTK: Receptor tyrosine kinase; GIST: Gastrointestinal stromal tumors; EGFR: Epithelial growth factor receptor; FFPE: Formalin fixed paraffin-embedded; DNA: Deoxyribonucleic acid; HE: Hematoxylin-eosin; IRS: Immuno-reactive-score; KRAS: V-Ki-RAS2 Kirsten rat sarcoma viral oncogene homolog; NRAS: Neuroblastoma RAS viral oncogene homolog; IHC: Immunohistochemistry; AEC: Chromogens 3-amino-9-ethylcarbazole; PBS: Phosphate-buffered saline; COSMIC: Catalogue of somatic mutations in cancer; HSF: Human splicing finder; SIFT: Sorting intolerant from tolerant; PROVEAN: Protein variation effect analyzer; mRNA: Messenger ribonucleic acid; $\Delta \mathrm{G}$ : Gibbs free energy; SNV: Single nucleotide variant; MAF: Minor allele frequency; dbSNP: Single nucleotide polymorphism database; SNV: Single nucleotide variant; MAF: Minor allele frequency; ICC: Interstitial cells of Cajal; SMC: Smooth muscle cells; UICC: International union against cancer; BRAF: V-raf murine sarcoma viral oncogene homolog B1; PIK3CA: Phosphatidylinositol-4,5-bisphosphate 3-kinase catalytic subunit alpha.
\end{abstract}

\section{Acknowledgements}

We thank all the members of the human and experimental pathology and biomedical and oncogenetic genomics laboratories of the Institut Pasteur de Tunis for their facilitation of this work.

\section{Author's contributions}

Study conception and design: NBJ, HTK, SB. Data acquisition: NBJ, HTK. Analysis and interpretation of data: NBJ, HTK, SB. Bioinformatic analysis and networking: NBJ, HTK. Technical experiment: NBJ, HY, NM, AJG and CBF. Full manuscript redaction: NBJ. Involvement in the drafting of the manuscript:
HTK, HY, NM, AJG, EF. Critical revision of the article: HTK, SA and SB. Submission procedure: NBJ. All authors read and approved the final manuscript.

\section{Funding}

This work was supported by the Tunisian Ministry of Public Health, the Tunisian Ministry of Higher Education and Scientific Research (LR16IPT05).

\section{Availability of data and materials}

All data generated or analyzed during this study are included in this published article.

\section{Ethics approval and consent to participate}

This study was carried out after the approval of the biomedical ethics committee of Institut Pasteur de Tunis (2017/6B///Cancer colorectal/V1).

\section{Consent for publication}

Consent to publish has been obtained from all authors.

\section{Competing interests}

The authors declare that they have no competing interests.

\section{Author details}

${ }^{1}$ Laboratory of Human and Experimental Pathology, Faculty of Science of Tunis, Institut Pasteur de Tunis, University Tunis El Manar, Tunis, Tunisia.

${ }^{2}$ Laboratory of Human and Experimental Pathology, Faculty of Medicine of Tunis, Institut Pasteur de Tunis, University Tunis El Manar, Tunis, Tunisia.

${ }^{3}$ Laboratory of Biomedical Genomics and Oncogenetics, Institut Pasteur de

Tunis, University Tunis El Manar, Tunis, Tunisia.

Received: 18 June 2020 Accepted: 6 November 2020

Published online: 19 November 2020

\section{References}

1. Abdel Ghafar MT, Gharib F, Abdel-Salam S, Elkhouly RA, Elshora A, Shalaby $\mathrm{KH}$, et al. Role of serum Metadherin mRNA expression in the diagnosis and prediction of survival in patients with colorectal cancer. Mol Biol Rep. 2020;47(4):2509-19. https://doi.org/10.1007/s11033-020-05334-5.

2. El-Guindy DM, Wasfy RE, Abdel Ghafar MT, Ali DA, Elkady AM. Expression in gastric carcinoma: association with tumor proliferation, angiogenesis and survival. J Egypt Natl Cancer Inst. 2019;31(1):3. https://doi. org/10.1186/s43046-019-0005-0.

3. Ostman A. PDGF receptors-mediators of autocrine tumor growth and regulators of tumor vasculature and stroma. Cytokine Growth Factor Rev. 2004;15(4):275-86. https://doi.org/10.1016/..cytogfr.2004.03.002.

4. Wehler TC, Frerichs K, Graf C, Drescher D, Schimanski K, Biesterfeld S, et al. PDGFRa/ $\beta$ expression correlates with the metastatic behavior of human colorectal cancer: a possible rationale for a molecular targeting strategy. Oncology Rep. 2008;19(3):697-704. https://doi.org/10.3892/or.19.3.697.

5. Brand TM, lida M, Wheeler DL. Molecular mechanisms of resistance to the EGFR monoclonal antibody cetuximab. Cancer Biol Ther. 2011;11(9):77792. https://doi.org/10.4161/cbt.11.9.15050.

6. Ubink I, Bloemendal HJ, Elias SG, Brink MA, Schwartz MP, Holierhoek YCW, et al. Imatinib treatment of poor prognosis mesenchymal-type primary colon cancer: a proof-of-concept study in the preoperative window period (ImPACCT). BMC Cancer. 2017;17(1):282. https://doi.org/10.1186/ s12885-017-3264-y.

7. Ozawa T, Brennan CW, Wang L, Squatrito M, Sasayama T, Nakada M, et al. PDGFRA gene rearrangements are frequent genetic events in PDGFRAamplified glioblastomas. Genes Dev. 2010;24(19):2205-18. https://doi. org/10.1101/gad.1972310.

8. Carvalho I, Milanezi F, Martins A, Reis RM, Schmitt F. Overexpression of platelet-derived growth factor receptor alpha in breast cancer is associated with tumour progression. Breast Cancer Res. 2005;7(5):R788-95. https://doi.org/10.1186/bcr1304.

9. Heldin $\mathrm{CH}$, Lennartsson J, Westermark B. Involvement of platelet-derived growth factor ligands and receptors in tumorigenesis. J Intern Med. 2018;283(1):16-44. https://doi.org/10.1111/joim.12690.

10. Shinagawa K, Kitadai Y, Tanaka M, Sumida T, Onoyama M, Ohnishi M, et al. Stroma-directed imatinib therapy impairs the tumor-promoting effect of 
bone marrow-derived mesenchymal stem cells in an orthotopic transplantation model of colon cancer. Int J Cancer. 2013;132(4):813-23. https ://doi.org/10.1002/ijc.27735.

11. Bardelli A, Siena S. Molecular mechanisms of resistance to cetuximab and panitumumab in colorectal cancer. J Clin Oncol. 2010;28(7):1254-61. https://doi.org/10.1200/JCO.2009.24.6116.

12. Szerlip NJ, Pedraza A, Chakravarty D, Azim M, McGuire J, Fang Y, et al. Intratumoral heterogeneity of receptor tyrosine kinases EGFR and PDGFRA amplification in glioblastoma defines subpopulations with distinct growth factor response. Proc Nat Acad Sci. 2012;109(8):3041-6. https:// doi.org/10.1073/pnas.1114033109.

13. Chakravarty D, Pedraza AM, Cotari J, Liu AH, Punko D, Kokroo A, et al. EGFR and PDGFRA co-expression and heterodimerization in glioblastoma tumor sphere lines. Sci Rep. 2017;7(1):1-10. https://doi.org/10.1038/s4159 8-017-08940-9.

14. Bertotti A, Papp E, Jones S, Adleff V, Anagnostou V, Lupo B, et al. The genomic landscape of response to EGFR blockade in colorectal cancer. Nature. 2015;526(7572):263-7. https://doi.org/10.1038/nature14969.

15. Schimanski CC, Zimmermann T, Schmidtmann I, Gockel I, Lang H, Galle $P R$, et al. K-ras mutation status correlates with the expression of VEGFR1, VEGFR2, and PDGFRalpha in colorectal cancer. Int J Colorectal Dis. 2010;25(2):181-6. https://doi.org/10.1007/s00384-009-0843-7.

16. Venselaar H, Te Beek TA, Kuipers RK, Hekkelman ML, Vriend G. Protein structure analysis of mutations causing inheritable diseases. An e-Science approach with life scientist friendly interfaces. BMC Bioinform. 2010;11(1):548. https://doi.org/10.1186/1471-2105-11-548.

17. Zuker M. Mfold web server for nucleic acid folding and hybridization prediction. Nucleic Acids Res. 2003;31(13):3406-15. https://doi.org/10.1093/ nar/gkg595.

18. Zuker M, Jacobson AB. Using reliability information to annotate RNA secondary structures. RNA. 1998;4(6):669-79. https://doi.org/10.1017/ s1355838298980116.

19. Bache KG, Slagsvold T, Stenmark H. Defective downregulation of receptor tyrosine kinases in cancer. EMBO J. 2004;23(14):2707-12. https://doi. org/10.1038/sj.emboj.7600292.

20. Heldin C-H, Östman A, Rönnstrand L. Signal transduction via plateletderived growth factor receptors. Biochim Biophys Acta (BBA) Rev Cancer. 1998;1378(1):F79-113. https://doi.org/10.1016/S0304-419X(98)00015-8.

21. Chen D, Zuo D, Luan C, Liu M, Na M, Ran L, et al. Glioma cell proliferation controlled by ERK activity-dependent surface expression of PDGFRA. PLoS ONE. 2014;9(1):e87281. https://doi.org/10.1371/journal.pone.00872 81.

22. Bahlawane C, Eulenfeld R, Wiesinger MY, Wang J, Muller A, Girod A, et al. Constitutive activation of oncogenic PDGFR alpha-mutant proteins occurring in GIST patients induces receptor mislocalisation and alters PDGFR alpha signalling characteristics. Cell Commun Signal. 2015;13:21. https://doi.org/10.1186/s12964-015-0096-8.

23. Clarke ID, Dirks PB. A human brain tumor-derived PDGFR-alpha deletion mutant is transforming. Oncogene. 2003;22(5):722-33. https://doi. org/10.1038/sj.onc.1206160.

24. Haan S, Bahlawane C, Wang J, Nazarov PV, Muller A, Eulenfeld R, et al. The oncogenic FIP1L1-PDGFRalpha fusion protein displays skewed signaling properties compared to its wild-type PDGFR alpha counterpart. JAKSTAT. 2015;4(1):e1 062596. https://doi.org/10.1080/21623996.2015.1062596.

25. Bian Y-H, Huang S-H, Yang L, Ma X-L, Xie J-W, Zhang H-W. Sonic hedgehog-Gli1 pathway in colorectal adenocarcinomas. World J Gastroenterol WJG. 2007;13(11):1659. https://doi.org/10.3748/wjg.v13.111.1659.

26. Dai YC, Zhu XS, Nan QZ, Chen ZX, Xie JP, Fu YK, et al. Identification of differential gene expressions in colorectal cancer and polyp by CDNA microarray. World J Gastroenterol. 2012;18(6):570-5. https://doi.org/10.3748/ wjg.v18.6.570.

27. Li C, Wang Y, Lu S, Zhang Z, Meng H, Liang L, et al. MiR-34a inhibits colon cancer proliferation and metastasis by inhibiting platelet-derived growth factor receptor al pha. Mol Med Rep. 2015;12(5):7072-8. https://doi. org/10.3892/mmr.2015.4263.

28. Hanahan D, Weinberg RA. Hallmarks of cancer: the next generation. Cell. 2011;144(5):646-74. https://doi.org/10.1016/j.cell.2011.02.013.

29. van Pelt GW, Kjaer-Frifeldt S, van Krieken J, Al Dieri R, Morreau H, Tollenaar $\mathrm{R}$, et al. Scoring the tumor-stroma ratio in colon cancer: procedure and recommendations. Virchows Arch. 2018;473(4):405-12. https://doi. org/10.1007/s00428-018-2408-z.
30. Lawrie CH, Armesto M, Fernandez-Mercado M, Arestín M, Manterola L, Goicoechea I, et al. Noncoding RNA expression and targeted next-generation sequencing distinguish tubulocystic renal cell carcinoma (tc-rcc) from other renal neoplasms. J Mol Diag. 2018;20(1):34-45. https://doi. org/10.1016/j.jmoldx.2017.09.002.

31. Takazawa Y, Sakurai S, Sakuma Y, Ikeda T, Yamaguchi J, Hashizume Y, et al. Gastrointestinal stromal tumors of neurofibromatosis type I (von Recklinghausen's disease). Am J Surg Pathol. 2005;29(6):755-63. https:// doi.org/10.1097/01.pas.0000163359.32734.f9.

32. Duan J, Wainwright MS, Comeron JM, Saitou N, Sanders AR, Gelernter J, et al. Synonymous mutations in the human dopamine receptor D2 (DRD2) affect mRNA stability and synthesis of the receptor. Hum Mol Genet. 2003;12(3):205-16. https://doi.org/10.1093/hmg/ddg055.

33. Supek F, Minana B, Valcarcel J, Gabaldon T, Lehner B. Synonymous mutations frequently act as driver mutations in human cancers. Cell. 2014;156(6):1324-35. https://doi.org/10.1016/j.cell.2014.01.051.

34. Sharma Y, Miladi M, Dukare S, Boulay K, Caudron-Herger M, Gross M, et al. A pan-cancer analysis of synonymous mutations. Nat Commun. 2019;10(1):2569. https://doi.org/10.1038/s41467-019-10489-2.

35. Bartoszewski RA, Jablonsky M, Bartoszewska S, Stevenson L, Dai Q, Kappes J, et al. A synonymous single nucleotide polymorphism in DeltaF508 CFTR alters the secondary structure of the mRNA and the expression of the mutant protein. J Biol Chem. 2010;285(37):28741-8. https://doi. org/10.1074/jbc.M110.154575.

36. Zeng Z, Bromberg Y. Predicting functional effects of synonymous variants: a systematic review and perspectives. Front Genet. 2019;10:914. https://doi.org/10.3389/fgene.2019.00914.

37. Dai J, Yang L, Xu T, Si L, Cui C, Sheng X, et al. A Functional synonymous variant in PDGFRA is associated with better survival in acral melanoma. J Cancer. 2020;11(10):2945-56. https://doi.org/10.7150/jca.43010.

38. Garrigós C, Espinosa M, Salinas A, Osman I, Medina R, Taron M, et al. Single nucleotide polymorphisms as prognostic and predictive biomarkers in renal cell carcinoma. Oncotarget. 2017;8(63):106551. https://doi. org/10.18632/oncotarget.22533.

39. Li Z-Z, Wang F, Zhang Z-C, Wang F, Zhao Q, Zhang D-S, et al. Mutation profiling in chinese patients with metastatic colorectal cancer and its correlation with clinicopathological features and anti-EGFR treatment response. Oncotarget. 2016;7(19):28356. https://doi.org/10.18632/oncot arget.8541.

40. Shao R, Kato N, Lin L, Muroyama R, Moriyama M, Ikenoue T, et al. Absence of tyrosine kinase mutations in Japanese colorectal cancer patients. Oncogene. 2007;26(14):2133-5. https://doi.org/10.1038/sj.onc.1210007.

41. Xie J, Aszterbaum M, Zhang X, Bonifas JM, Zachary C, Epstein E, et al. A role of PDGFRa in basal cell carcinoma proliferation. Proc Nat Acad Sci. 2001;98(16):9255-9. https://doi.org/10.1073/pnas.151173398.

42. Maeda C, Hidaka E, Mori Y, Mukai S, Miyachi H, Sawada N, et al. Tumor diameter is an easy and useful predictor of recurrence in stage II colorectal cancer. Dig Surg. 2015;32(5):338-43. https://doi.org/10.1159/00043 1188.

43. Yasui M, Takemasa I, Miyake Y, Hata T, Ikeda M, Miyake Y, et al. Tumor size as an independent risk factor for postoperative complications in laparoscopic low anterior resection for advanced rectal Cancer: a multicenter Japanese study. Surg Laparosc Endosc Percut Tech. 2017;27(2):98-103. https://doi.org/10.1097/SLE.0000000000000377.

44. Cho T, Shiozawa E, Urushibara F, Arai N, Funaki T, Takehara Y, et al. The role of microvessel density, lymph node metastasis, and tumor size as prognostic factors of distant metastasis in colorectal cancer. Oncol Lett. 2017;13(6):4327-33. https://doi.org/10.3892/ol.2017.5959.

45. Yan Q, Zhang K, Guo K, Liu S, Wasan HS, Jin H, et al. Value of tumor size as a prognostic factor in metastatic colorectal cancer patients after chemotherapy: a population-based study. Fut Oncol. 2019;15(15):1745-58. https ://doi.org/10.2217/fon-2018-0785.

46. Santullo F, Biondi A, Cananzi FCM, Fico V, Tirelli F, Ricci R, et al. Tumor size as a prognostic factor in patients with stage lla colon cancer. Am J Surg. 2018;215(1):71-7. https://doi.org/10.1016/j.amjsurg.2017.03.038.

47. Huang B, Feng Y, Zhu L, Xu T, Huang L, Cai G. Smaller tumor size is associated with poor survival in stage II colon cancer: an analysis of 7,719 patients in the SEER database. Int I Surg. 2016;33Pt A:157-63. https://doi. org/10.1016/j.jijsu.2016.07.073

48. Lee SY, Kim CH, Kim YJ, Kim HR. Macroscopic serosal invasion and small tumor size as independent prognostic factors in stage IIA colon cancer. 
Int J Colorectal Dis. 2018;33(8):1139-42. https://doi.org/10.1007/s0038 4-018-3048-0

49. van der Sijp MP, Bastiaannet E, Mesker WE, van der Geest LG, Breugom AJ, Steup WH, et al. Differences between colon and rectal cancer in complications, short-term survival and recurrences. Int J Colorectal Dis. 2016;31(10):1683-91. https://doi.org/10.1007/s00384-016-2633-3.

50. Li JN, Zhao L, Wu J, Wu B, Yang H, Zhang HH, et al. Differences in gene expression profiles and carcinogenesis pathways between colon and rectal cancer. J Dig Dis. 2012;13(1):24-32. https://doi.org/10.111 1/j.1751-2980.2011.00551.x.

51. Mooi JK, Wirapati P, Asher R, Lee CK, Savas P, Price TJ, et al. The prognostic impact of consensus molecular subtypes (CMS) and its predictive effects for bevacizumab benefit in metastatic colorectal cancer: molecular analysis of the AGITG MAX clinical trial. Ann Oncol. 2018;29(11):2240-6. https:// doi.org/10.1093/annonc/mdy410.

52. Guinney J, Dienstmann R, Wang X, de Reynies A, Schlicker A, Soneson C, et al. The consensus molecular subtypes of colorectal cancer. Nat Med. 2015;21(11):1350-6. https://doi.org/10.1038/nm.3967.
53. Franz M, Rodriguez H, Lopes C, Zuberi K, Montojo J, Bader GD, et al. GeneMANIA update 2018. Nucleic Acids Res. 2018;46(W1):W60-4. https:// doi.org/10.1093/nar/gky311.

54. Van der Jeught $K$, Xu HC, Li YJ, Lu XB, Ji G. Drug resistance and new therapies in colorectal cancer. World J Gastroenterol. 2018;24(34):3834-48. https://doi.org/10.3748/wjg.v24.i34.3834.

55. Mamer SB, Chen S, Weddell JC, Palasz A, Wittenkeller A, Kumar M, et al. Discovery of high-affinity PDGF-VEGFR interactions: redefining RTK dynamics. Sci Rep. 2017;7(1):16439. https://doi.org/10.1038/s41598-01716610-z.

\section{Publisher's Note}

Springer Nature remains neutral with regard to jurisdictional claims in published maps and institutional affiliations.
Ready to submit your research? Choose BMC and benefit from:

- fast, convenient online submission

- thorough peer review by experienced researchers in your field

- rapid publication on acceptance

- support for research data, including large and complex data types

- gold Open Access which fosters wider collaboration and increased citations

- maximum visibility for your research: over $100 \mathrm{M}$ website views per year

At BMC, research is always in progress.

Learn more biomedcentral.com/submissions 